\title{
UMA ANÁLISE CRÍTICA AO PENSAMENTO PÓS-MODERNO: DA RACIONALIDADE FORMAL AO IRRACIONALISMO ${ }^{1}$
}

José Pereira de Sousa Sobrinho ${ }^{2}$

\begin{abstract}
RESUMO
No presente artigo propomo-nos analisar, em um contexto de crise crônica da sociedade do capital, os complexos superestruturais necessários à manutenção da estrutura social vigente. Apontando em particular para a constituição das correntes irracionalistas, fundamento nas concepções pós-modernas, enquanto mecanismo superestrutural de construção de uma consciência coletiva pautada na exacerbação do individualismo e no consenso entre classes sociais antagônicas, enquanto estratégia necessária do capital para sua continua reprodução.
\end{abstract}

Palavras chaves: crise do capital; irracionalismo; pós-modernidade.

\section{CRITICAL ANALYSIS TO THE POST-MODERN THOUGHT: FROM FORMAL RATIONALITY TO IRRATIONALISM}

\begin{abstract}
In the present paper, at a context of chronic crisis of the capital society, we intend to analyze the superstructure complexes which are necessary to the maintenance of the current social structure. Pointing, in a particular way, to the construction of irrationalism tendencies, which are foundation to the post-modern conceptions, as a superstructure mechanism of building of a collective consciousness based on the individualism rise and on the consensus between antagonist social classes, as necessary capital's strategy to its continuous reproduction.
\end{abstract}

Key-words: Capital crisis; Irrationalism; Post-modernity.

A crise financeira de 2008 voltou a balançar as estruturas do sistema capitalista e as convicções inabaláveis em torno do suposta eternidade da sociedade do capital. Por outro, o referido fenômeno histórico reafirma a validade da teoria marxiana, que interpreta as crises econômicas como resultado das contradições insolúveis do sistema capitalista. Expressas periodicamente na forma de violentas erupções, ressaltando o aspecto transitório do sistema.

A escolha pela análise da base materialista da sociedade capitalista nos fornece o caminho metodológico efetivo capaz não apenas denunciar o caráter falseador da realidade presente no discurso dominante como também a capacidade de apresentar a finalidade e a origem de tais produções culturais e científicas, permitindo interpretá-las ao mesmo tempo enquanto produto e produtor dessa forma social. Para tanto, tomaremos o percurso metodológico marxiano como elemento norteador de nossa reflexão das condições históricas do desenvolvimento da razão burguesa, passando pela análise das formulações pós-modernas.

\footnotetext{
${ }^{1}$ Pesquisa financiada pela CAPES.

${ }^{2}$ Doutorando em Educação pelo Programa de Educação Brasileira pela Universidade Federal do Ceará.
} 


\section{Realidade Objetiva e Pensamento Burguês: do Desenvolvimento da Razão à Decadência Irracional.}

O título de nosso tópico do "desenvolvimento da razão à decadência irracional” fornece propositalmente uma imagem um tanto contraditória a respeito do desenvolvimento da razão burguesa, a qual adquire sentido quando observamos a validade das análises de Lukács (1979) quando este afirma que a burguesia, no momento de sua ascensão histórica ao posto de classe dominante, cumpre uma função essencialmente revolucionária ao subverter os valores éticos, estéticos e culturais do modelo produtivo precedente. Assim, a burguesia "destruiu as relações feudais, patriarcais e idílicas. Rasgou todos os complexos e variados laços que prendiam o homem feudal a seus "superiores naturais", para só deixar subsistir, de homem para homem, o laço do frio interesse, as duras exigências do 'pagamento à vista'”. (MARX, 2002, p. 42).

As transformações materiais impostas pela produção voltada à extração do mais-valor cumpri também no interior da cultura e da ciência uma função essencialmente revolucionária, durante o primeiro período de ascensão burguesa, o qual perdurou até o ano de 1848 . O conteúdo essencialmente progressista do pensamento burguês desse período se fez necessário para garantir a evolução econômica, patrocinada pelo avanço técnico essencialmente centrado no desenvolvimento da produtividade. Cunhada na agudização da relação entre homem e máquina, gestão científica do trabalho industrial. Já, no campo das ciências sociais a produção científica burguesa torna-se essencialmente uma arma contra a "irrazão" (desrazão) feudal no interior da luta de classes. Particularmente o caráter progressista da ciência burguesa no referido período está diretamente associado ao conceito de totalidade, presentes em formulações vinculadas à reflexão sobre valores humanos universais, em oposição ao pensamento feudal. Isto era possível devido ao

caráter objetivamente progressista do capitalismo permiti[r] aos pensadores que se colocavam do ângulo do novo a compreensão do real como síntese de possibilidade e realidade, como totalidade concreta em constante evolução. Sem compromissos com a realidade imediata, os pensadores burgueses não limitavam a razão à classificação do existente, mas afirmavam seu ilimitado poder de apreensão do mundo em permanente devir. De Bruno a Hegel, passando por Spinoza e Vico, observamos no pensamento da época o nascimento de uma nova dialética racional, que apresentava - em relação à dialética primitiva dos gregos - o inegável mérito de se basear sobre o reflexo de um ser social bem mais complexo e articulado [...]. A compreensão do real como totalidade submetida a leis e a afirmação da historicidade dos processos objetivos são momentos determinantes da nova racionalidade em elaboração (COUTINHO, 2010, p. 25-26).

\begin{tabular}{|l|l|l|l|l|}
\hline Q & Anista \\
\hline
\end{tabular}


O caráter essencialmente revolucionário da burguesia, no trato com o conhecimento e com a cultura, transmuta-se em um conteúdo reacionário logo que esta se estabelece como nova classe dominante, consolidando seu domínio político. Nessa condição, enxerga no proletariado a possibilidade de um conflito que assuma proporções capazes de ameaçar seu domínio.

O interesse burguês impõe a superação da razão comprometida em desvelar o conteúdo do real em sua essência, apreendido por pesquisadores desinteressados, os quais são substituídos por espadachins mercenários, onde "a investigação científica imparcial cedeu lugar à consciência deformada e às intenções perversas apologéticas" (MARX, 2006, p. 24). Concretiza-se, portanto, na prevalência do pensamento apologético do atual sistema, com vista a garantir a estabilidade da burguesia enquanto a classe dominante. A decadência iminente do pensamento burguês nesse período, se expressa no agnosticismo, em sua negação do saber cientifico em torno da "essência verdadeira do mundo e da realidade", inclusive revogando sua necessidade sobre o argumento da inutilidade. Assim, a produção do conhecimento só deveria se "preocupar com as aquisições das ciências, especializadas e separadas umas das outras, conhecimentos indispensáveis do ponto de vista da vida prática de todos os dias". Nesse sentido, o papel da filosofia devia "limitar-se a vigiar para que ninguém ultrapasse os limites definidos pelas ciências e para que ninguém ouse tirar das ciências econômicas e sociais conclusões que poderiam desacreditar o regime". Assim, o agnosticismo "repudia por princípio todas as pesquisas que tendem a elaborar uma concepção coerente do mundo, pois uma visão de conjunto definiria os limites traçados pela ciência, que considera como autoridade suprema" (LUKÀCS, 1979, p. 33- 34).

Assim, a decadência do pensamento burguês, expressa no agnosticismo, tem como fruto a negação da continuidade do desenvolvimento da razão alcançado durante seu período de ascensão, o que repercute na suposta impossibilidade da razão de ofertar respostas efetivas às grandes questões da existência humana, que dão lugar ao determinismo social mais rigoroso e à chamada racionalidade puramente técnica ou razão formal.

Este novo conteúdo histórico do pensamento burguês é fundado e fundante da estabilização social da burguesia enquanto nova classe dominante, vindo aprofundar as relações de produção mediadas por uma rígida divisão social do trabalho. Sobre esse modelo de organização do trabalho, vida e teoria estão em oposição. Coadunando para uma produção cultural e científica que se destaca por negar os problemas centrais da vida humana, ao refutar a possibilidade de reflexão crítica em torno da estrutura interna da ordem social vigente.

\begin{tabular}{|l|l|l|l|l|}
\hline Q & Dovista \\
\hline
\end{tabular}


Por sua vez, o caráter reacionário e contraditório da burguesia se manifesta na institucionalização da educação pública incapaz de garantir o acesso à classe trabalhadora ao conhecimento historicamente acumulado pela humanidade, na medida em que o conhecimento disponibilizado na escola é constituído na esfera da denominada razão formal - desenvolvido sob o domínio burguês - responsável pela análise pragmática dos processos de trabalho em sua estrutura fragmentada. Ou seja, o trabalhador está alienado da possibilidade de refletir para além da aparência das coisas, o que lhe é imposto pela deformação do ser social sob o jugo da divisão social do trabalho, que lhe permite o acesso apenas a essa razão puramente técnica necessária às operações simples do trabalho.

Lukács citado por Costa (2004, p. 73), refere-se ao racionalismo técnico gerado pelo pensamento agnóstico, como o racionalismo cerrado que não "é certamente mais que a formulação no pensamento dos pequenos fins imediatos da vida profissional capitalista, a filosofia da rodilha na maquinaria, cuja rotação nada tem que ver com um processo conjunto da evolução humana nem com problemas da vida individual."

Os valores progressistas do pensamento burguês deviam ser abandonados na luta defensiva contra o proletariado. O desenvolvimento da razão combina-se com o desenvolvimento do saber puramente técnico, fragmentado em diversos campos especializados do conhecimento, no qual a realidade em sua imediatez é apreendida. As reformulações sobre a verdade e a refutação da capacidade da ciência de apreendê-la, efetivadas no interior do pensamento burguês decadente, estabelecem uma relação fetichizada entre sujeito e objeto, no qual a apreensão do reflexo do objeto se resume à apreensão puramente imediata na superfície do fenômeno, negando o seu conteúdo histórico e social.

Tal formulação adquire forma quando, no delinear da razão burguesa, os diversos campos fragmentários da racionalidade formal são tomados como o único meio para se atingir a uma suposta verdade. O caráter defensivo de tal formulação está no fato de que tudo que escapa à apreensão dos campos de conhecimento especializado tem vetada a sua apreensão pela razão, ou seja, lhe é vetada a possibilidade de apreensão científica. Coutinho (2010) destaca sobre essa ferramenta do pensamento burguês a sua especial validade em negar o debate sobre conteúdos fundamentais da realidade social com ênfase sobre a contradição, devido a sua centralidade para compreensão do modus operandi da sociedade do capital. Essa premissa se expressa no positivismo agnóstico, expressos por um lado na sociologia positivista e economia vulgar que

desligando-se da história e formalizando ao extremo seu objeto, afastam de suas preocupações qualquer referência à objetividade das contradições no capitalismo; a filosofia, por outro lado, transformando-se em pura epistemologia (isto é, recusando

\begin{tabular}{|l|l|l|l|l|}
\hline Revista Dialectus & Ano 2 & n. 5 & Agosto - Dezembro 2014 & p. 12-24 \\
\hline
\end{tabular}


cidadania filosófica à ontologia e à ética), propõe-se como tarefa limitar a validade da Razão àqueles domínios do real que possam ser homogeneizados, formalizados, manipulados, sem consideração pela sua natureza objetivamente contraditória (Coutinho, 2010, p. 50-1).

Ainda para Coutinho (2010, p. 50-51) a produção de uma racionalidade formal na qual o objeto encontra-se depurado “de contradições, vem juntar-se uma 'razão' que considera todos os momentos ontológicos da realidade como incognoscíveis ou irracionais", alcança-se uma miséria da razão, com seu empobrecimento e extrema formalização, desembocando em um agnosticismo que oculta o real. Nesse ponto do desenvolvimento da racionalidade formal ocultação do real - encontramos o nexo que conduz ao irracionalismo como a segunda vertente do pensamento burguês. Mas, longe de expressarem uma contradição em sua atuação no interior da sociedade burguesa - racionalidade formal e irracionalismo -, afirmam-se como complementares. A incoerência aparente de nossa afirmação é logo dispersa quando observamos que a função da irracionalidade está em reafirmar a impossibilidade de inteligibilidade de esferas da vida que escapam à apreensão da razão formal das ciências especializadas. Assim, racionalismo formal e irracionalismo, isolados ou em conjunto, são o meio de negação da possibilidade de apreensão intelectual de uma visão totalizante do mundo. Ou seja, trata-se da negação da razão dialética surgida no próprio período de ascensão da burguesia, assimilada por Marx, que oferta à razão um conteúdo revolucionário em favor da classe trabalhadora.

Contudo, o método dialético, negado pela razão burguesa, nos ensina que a compreensão do processo de desenvolvimento das suas referidas correntes de pensamento estão associados às próprias condições objetivas do real. Conforme Lukács (1979) descreve, a origem da razão formal no período pós 1848, como marcada pela estabilidade burguesa e a consequente luta defensiva contra o proletariado. Para o autor húngaro o amplo desenvolvimento da corrente irracionalista na esfera da produção cultural burguesa dá-se especialmente a partir de 1914, a data é emblemática pelo início da $1^{\text {a }}$ Guerra Mundial, mas, a referida data marca a consolidação do sistema capitalista em sua fase imperialista. Esta corresponde a um momento histórico no qual emergem as contradições internas do sistema, onde a estabilidade adquirida no período anterior dá lugar a uma extrema instabilidade do regime burguês quando as verdades estabelecidas pela intelectualidade dominante, a respeito da superioridade e eternidade do sistema burguês passam a ser questionadas.

Segundo Lukács (1979) é sobre a base social do imperialismo, marcado por um extremo ceticismo, que surge um agnosticismo relativista que conduz a filosofia irracionalista, a qual

\begin{tabular}{|l|l|l|l|l|}
\hline Q & Dovista \\
\hline
\end{tabular}


faz uso de métodos suprarracionais ao mesmo tempo em que afirma o antirracionalismo como meio de negação da possibilidade de aferição do real. Nesse percurso irracionalista, a fabricação de mitos é o meio encontrado para que as construções puramente idealistas possam assumir um papel da realidade, na explicação dos fenômenos objetivos. Assim, o mito opõe-se ao conhecimento científico; dissimulando e tornando obscuras as consequências sociais das aquisições da ciência. Para tanto, o mito impõe-se como

\begin{abstract}
uma essência superior à que é acessível ao conhecimento científico e que vai até mesmo condenar a ciência. A função social da ideologia, isto é, dos mitos, é, portanto, [...]: sugerir uma concepção do mundo que corresponda à da filosofia do imperialismo, onde quer que a ciência se mostre incapaz de oferecer uma visão de conjunto, e substituir a perspectiva oferecida pela ciência, cada vez que esta contradisser a concepção proposta pela filosofia paradoxal do estágio do imperialismo: a filosofia mantém de um lado a teoria do conhecimento do idealismo subjetivo herdada do agnosticismo, mas, por outro lado, estamos em presença de uma função completamente nova desse agnosticismo, função que consiste em criar um novo pseudo-objetivismo, franqueando o limite que o separa do mito (Lukács (1979, p. 50-51).
\end{abstract}

O fato é que o abandono incontornável do pensamento burguês ao conceito de totalidade e os limites impostos pela ciência especializada e fragmentária ao avanço do conhecimento abrem espaço para as construções metodológicas arbitrárias no interior do pensamento irracionalista que ofertam as suas formulações subjetivas um pretenso conteúdo de objetividade, originando a pseudo-objetividade referida acima por Lukács (1979). Tal estratagema apenas torna-se possível diante da negação da validade ou relativização da razão cientifica. Essa formulação metodológica no campo desta corrente filosófica permite a Lukács (1979, p. 57) desvendar o conteúdo interno da filosofia irracionalista, quando ele mostra o

\begin{abstract}
elemento mais importante da ideologia irracionalista: transformar, mistificando-a, a condição do homem do capitalismo imperialista em uma condição humana geral e universal. O cumprimento desta tarefa exige um desdobramento do método. Tudo que é social, racional e conforme às leis da evolução será declarado inumano e inimigo da personalidade. A personalidade será declarada anti-racional e irracional por sua própria natureza. [...] Com efeito, desde que se conseguiu opor a razão, inumana e inferior, à realidade superior, humana e irracional, capitalismo e socialismo apresentam-se como duas entidades inteiramente semelhantes, que se colocam num mesmo plano, posto que ambas foram criadas pela fria razão. Ambos, contudo, devem ser combatidas, em nome da personalidade, categoria puramente individual.
\end{abstract}

Tal conteúdo ideológico adquire forma na filosofia de Nietsche, Jaspers, assim como em sua continuidade de cunho existencialista, cujos maiores expoentes foram Heidegger, Sartre, Merleau-Ponty e Simone de Beauvoir. Os três últimos, que se empenharam em vincular suas formulações filosóficas ao marxismo, não puderam desterrar de sua base filosófica o conteúdo irracionalista e essencialmente de negação do socialismo. No recuo da corrente

\begin{tabular}{|c|c|c|c|c|}
\hline Q Rovista Dialectus & Ano 2 & n. 5 & Agosto - Dezembro 2014 & p. $12-24$ \\
\hline
\end{tabular}


existencialista, Coutinho (2010) encontra um dos elementos pelo qual emerge o estruturalismo e, posteriormente, o pós-estruturalismo.

O segundo elemento apontado por Coutinho (2010) para a ascensão estruturalista está na base objetiva do pós Segunda Guerra Mundial, no qual o positivismo pretende fundar uma nova visão de mundo que se adeque às transformações impostas pelo sistema do capital em seu processo de expansão e acumulação. As transformações apontadas pelo o autor referem-se às estratégias encontradas pelo capital para a contenção de suas crises periódicas, as quais passam pela alteração do foco de intervenção da racionalidade técnica efetivada até o momento no campo produtivo, para intervir no campo do consumo como sua nova estratégia para consolidar e estabilizar a taxa de lucro do sistema. Já que a racionalidade formal obteve êxito ao revolucionar constantemente as capacidades produtivas no interior do sistema capitalista, elevando ao extremo a sua capacidade de produção. A suposta solução almejada pelo sistema, está na imposição - enquanto garantia do processo de reprodução do valor -, de necessidades artificiais, mediadas pela racionalidade formal. Consolidando uma manipulação da individualidade e da vida privada, a qual deve ser submetida aos anseios do sistema capitalista, o tempo livre é transformado em tempo de consumo.

\section{Origem do Estruturalismo à Ruptura do Irracionalismo Pós-Moderno}

Sobre essa base objetiva de transformações no interior do sistema capitalista está o marco originário do estruturalismo, o qual surge com Lévi-Strauss. Anderson (1987) apresentanos o conteúdo demarcatório de sua obra ao referir-se à força argumentativa do autor francês que defende a igualação das diferentes sociedades humanas - no campo da dignidade. A base de sua defesa está nas supostas propriedades invariantes das mentes humanas, o que é defendido como uma ofensiva ferrenha à historicidade e a todo e qualquer progresso da humanidade. $\mathrm{O}$ ataque ao humanismo e à história, desenvolvido por Lévi-Strauss, sustenta-se sobre o recurso do mito, ofertando, portanto, continuidade ao pensamento irracionalista anterior. Para tanto, o autor afirma que a razão dialética é o mito moderno das civilizações contemporâneas, o qual está em equivalência aos mitos primitivos sem qualquer distinção de superioridade entre as duas formulações humanas.

A negação da razão dialética, no seio da corrente estruturalista, tem suas raízes na base objetiva imposta pela sociedade do capital, na qual a razão - racionalismo formal - passa a ser interpretada como essencialmente negativa quando seu campo de intervenção se volta para a

\begin{tabular}{|l|l|l|l|l|}
\hline Q & Dovista \\
\hline
\end{tabular}


manipulação da subjetividade enquanto mediação para a imposição do consumo em favor da taxa de lucro do capital. Todavia o alcance de tal conclusão passa pela negação de qualquer reflexão ontológica, assim como de qualquer racionalidade moderna associada ao iluminismo, negando desde os métodos de aferição do real, como também qualquer possibilidade de apreensão da verdade, do racional, da objetividade.

Para tanto, a linguagem - a partir da apreensão das formulações de Suassure analisadas por Anderson (1987) - torna-se para Lévi-Strauss o paradigma central para a apreensão da realidade. Em Lacan, as analogias entre linguagem e estruturas do real iniciadas por Lévi Strauss - no caso deste no campo da antropologia - são ampliadas para o campo da psicanálise, onde logo a linguagem torna-se o paradigma determinante não apenas das relações sociais, mas é o próprio paradigma fundante do ser social. O novo paradigma para a interpretação do real é evidente na passagem a seguir na qual Coggiola (2001, p. 58), citando Pierre Fougeyrollas, confirma a centralidade da linguagem na obra de Lacan, expressando que

\footnotetext{
“o inconsciente está estruturado como uma linguagem”, ou seja, que a linguagem precede ao inconsciente, isto é, ao ser humano, quer dizer, que no "no principio era o Verbo, e o Verbo se fez carne". Lacan, por outro lado, escreveu de fato que "é de fato o verbo que está no princípio", e ainda que "é o mundo das palavras que cria o mundo das coisas".
}

Desta formulação metodológica podemos deduzir que a negação da possibilidade apreensão do real é originada na negação dos fundamentos materiais enquanto seus determinantes. A consequência deste fato está na compreensão do real concreto enquanto simples aparência imediata, ou seja, como um todo fragmentado e caótico. O verbo, como formador da carne, reflete-se na desrazão filosófica da pura análise do discurso. O irracionalismo - expressão do pensamento decadente da burguesia - afirma a impossibilidade de apreensão do real e nega à ciência humana o seu propósito histórico de entender a coisa em sua essência. A centralidade da linguagem impõe a análise do discurso como a única tarefa "coerente" da ciência e, como afirma Coggiola (2001), não se investiga a coisa-em-si, mas exatamente o nome da coisa. A teoria não possui exterioridade, a ciência é incapaz de efetivar um espelhamento do real.

Anderson (1987) também faz coro à crítica da centralidade da linguagem presente nas obras de Lévi-Strauss, questionando essencialmente as apropriações da estrutura lingüística desenvolvida por Suassure - apropriações questionadas pelo próprio pai da linguística levadas às últimas consequências nas analogias desenvolvidas pelos autores estruturalistas com outras esferas da vida. Assim, entende que as analogias descobertas por Lévi-Strauss, na sua

\begin{tabular}{|l|l|l|l|l|}
\hline Qovista Dialectus & Ano 2 & n. 5 & Agosto - Dezembro 2014 & p. 12-24 \\
\hline
\end{tabular}


ampliação das categorias linguísticas para a antropologia, cedem ao menor exame crítico. Isto porque 0

\begin{abstract}
parentesco não pode ser comparado à linguagem como sistema de comunicação simbólica no qual as mulheres e palavras são respectivamente "trocadas", como sustentaria Lévi-Strauss, dado que nenhum locutor transfere vocabulário para nenhum interlocutor, mas pode reutilizar livremente todas as palavras "dadas", tantas vezes quanto desejar posteriormente, ao passo que os casamentos - ao contrário das conversas - são geralmente obrigatórios: as esposas não são recuperáveis por seus pais após a cerimônia. A terminologia de "troca" autoriza menos ainda uma supressão da economia: e se pode supor que, na maioria das sociedades, há pelo menos uma grosseira equivalência de palavras e mulheres com locutores e família, isso é evidentemente falso em relação aos bens. Em outras palavras, nenhuma economia pode, de forma alguma, ser primariamente definida em termos de troca: a produção e a propriedade são sempre prioritárias. A fórmula triádica de Lévi-Strauss opera, na verdade, para encobrir as relações de poder, exploração e desigualdade inerentes, não só às economias mais primitivas, para não falar da nova civilização do capital, mas também a toda ordem familiar ou sexual conhecida por nós, onde a conjugalidade está presa à propriedade, e a feminilidade à subordinação (ANDERSON, 1987, p. 49-50).
\end{abstract}

As analogias arbitrárias desenvolvidas no interior do pensamento burguês tem, segundo Anderson (1987, p. 48), sua continuidade sob o contexto do maio de 1968 - marcado pela revolta de estudantes e trabalhadores - quando se desenha a ruptura formulada por Derrida no interior do estruturalismo que acaba por conceber o pós-estruturalismo levando às últimas consequências a centralidade da linguagem, já que o autor francês rejeitou a "noção de linguagem como um sistema estável de objetivações, mas radicalizou suas pretensões como soberana universal do mundo moderno, como o decreto verdadeiramente imperial de que "não há nada fora do texto', 'nada além do texto, nenhum pretexto que não seja texto"”.

Lacan e Foucault, importantes autores no bojo do estruturalismo, aderem às formulações de Derrida que aponta o fim da "autonomia relativa residual do significado", fazendo da língua um processo onde "todo significado está também na posição de significante" (ANDERSON, 1987, p. 53) - que deságua para a superação da verdade, já que a palavra individual é a verdade. Portanto, não existe verdade, realidade ou razão para além de sua posição puramente individual, pois a palavra - a fala - tem sua efetivação no âmbito essencialmente individual, significando que não existe essência independente do sujeito, melhor dizendo, não existe essência.

Diante dessa formulação, Tonet (2009) nos apresenta o desenvolvimento do irracionalismo na história das ideias filosóficas quando afirma que se passa da negação da possibilidade de aferição da coisa-em-si defendida por Kant, para a completa negação de uma essência da coisa-em-si. Nesse sentido, a pós-modernidade afirma a impossibilidade de apreensão da essência do real pela negação de qualquer essência. Consentaneamente, prevalece

\begin{tabular}{|l|l|l|l|l|}
\hline Q & Dovista \\
\hline
\end{tabular}


à análise do discurso e a supremacia da linguagem como paradigma determinante de análise científica.

Podemos aferir que, diante da propagada impossibilidade de reconstrução do real no campo do ideal, a miséria da razão burguesa recai sobre as análises epistemológicas que recorrem a recursos como "genealogia do discurso" e a descrição de suas "epistemes", o que em nossa reflexão significa apenas a pura análise do discurso em si como meio para apreensão de uma pseudo-objetividade. A reflexão centrada sobre como se constrói o discurso, em detrimento das questões materiais determinantes em um contexto social de crise, conduz à miséria científica burguesa, como uma miséria literária travestida de ciência. A negação da história é expressa na descrição do cotidiano imutável, no tempo presente perpetuo, na metafísica do presente como expressa Moraes; Evangelista; Torriglia (2003, p. 157), os mesmo indicam esse recuo da teoria como a inauguração de uma época "cética e pragmática dos textos e das interpretações que não podem mais expressar ou, até mesmo, se aproximar da realidade, constituindo-se em simples relatos ou narrativas que, presos às injunções de uma cultura, acabam por arrimar-se no contingente e na prática imediata”.

As narrativas do cotidiano expressam a aparência caótica de uma realidade fragmentada. Concretizando-se em uma visão puramente fenomênica do real, o irracionalismo burguês é incapaz de ausentar-se da pura reflexão do discurso que apenas confirma o real como um caos esfacelado em suas múltiplas determinações sem um vínculo totalizante. Tonet (2009) advoga nesse processo a própria negação da apreensão da totalidade, assim como a negação da possibilidade de apreensão da realidade concreta, ou seja, da verdade, que não passaria de uma infinidade de fragmentos aleatórios, sendo qualquer tentativa de aferir sistematicamente esse todo fragmentário nada mais do que a aplicação intersubjetiva do método, ou seja, trata-se do objeto construído pelo sujeito, o sujeito aferindo um conteúdo a coisa ao invés de apreender o conteúdo da coisa.

O pós-estruturalismo promove em sua investida metodológica a perca, por parte de seu paradigma de análise, de qualquer referência exterior à linguagem. O resultado de seu avanço antimaterialista está na atenuação da verdade, conduzida através da fragmentação do conhecimento, combinando-se à alegação da impossibilidade de apreensão aos fundamentos do real a suposta inviabilidade de compreensão racional das intercalações entre os diversos complexos sociais. Assim, o pós-estruturalismo nega o metabolismo capitalista em seu movimento incessante de expansão e acumulação privada da riqueza social; nega também a totalidade das relações sociais, a história da luta de classes, em um momento histórico de

\begin{tabular}{|l|l|l|l|l|}
\hline Rovista Dialectus & Ano 2 & n. 5 & Agosto - Dezembro 2014 & p. 12-24 \\
\hline
\end{tabular}


ofensiva do capital sobre a classe proletária fragmentada em sua organização após a instituição do modelo neoliberal de trabalho precarizado.

Portanto, o irracionalismo pós-moderno efetiva a negação do todo social, impondo um obstáculo ideológico e cultural à reorganização da classe revolucionária na luta histórica pelo socialismo. A luta política radical e de classe é substituída neste contexto de fragmentação por uma esfera política estilhaçada em "uma miríade de movimentos com reivindicações particulares e aparentemente não integradas. A luta pelo poder político central - a conquista ou a destruição do Estado - foi substituída pelas infinitas questões dos "poderes locais". (COSTA, 2004, p. 66).

A análise de Costa (2004) afere na pós-modernidade a declaração burguesa do fim da luta de classes em sua articulação totalizante, e como consequência a proclamação da eternidade do capital, restando como alternativa a sua humanização. Ou seja, ao afirmar socialismo e capitalismo como as duas tragédias da razão moderna, restam aos pósestruturalistas defender o terceiro caminho, o qual trata-se de uma tentativa de reformar o sistema do capital. Essa tese, na verdade, tem como essência apenas a manutenção do capital diante da impossibilidade material de reformá-lo ou humanizá-lo.

Desse percurso de negação do socialismo enquanto alternativa viável ao sistema do capital desenvolve-se o novo mecanismo de regulação social do capital constituído sobre a mediação de um discurso ideológico que conduz à supressão dos elementos radicais da luta de classe, ao impor a inviabilidade epistemológica da luta revolucionária e da constituição de uma sociedade qualitativamente distinta ao modelo capitalista. O recuo da teoria imposto pelo pensamento decadente burguês implica no retrocesso na luta socialista e no avanço do capital sobre uma classe desarmada pelo desemprego estrutural e pelas derrotas históricas do sindicalismo combativo. O novo modelo de controle societário conduz à naturalização do sistema capitalista e ao fetichismo da diversidade, associada à negação do conflito de classes enquanto resultado da pulverização do poder e das opressões - opressão e poder que se efetivam no oprimido e no dominado e em todos os espaços e relações da vida social. Portanto, o movimento do pensamento irracionalista burguês que busca encobrir as relações de poder entre classes sociais existentes nos diversos modelos de organização social formulado pelo estruturalismo de Lévi-Strauss, tem continuidade em sua versão pós-moderna.

Assim, a negação da luta radical instaura-se no cotidiano coletivo sobre o filtro pragmático que elimina todas as análises ou termos que possuem uma concepção crítica a este modelo social. Desde o vocabulário, as organizações de classe, as relações de opressão e o

\begin{tabular}{|l|l|l|l|l|}
\hline Q & Dovista \\
\hline
\end{tabular}


cotidiano são vinculados ao vazio. Tudo o que se instaura sobre a aura do conflito de classes é negado, passando a construção do consenso coletivo efetivado na cooptação de intelectuais e nas políticas reformistas. Portanto, a teoria pós-moderna instaura de forma indireta uma apologia a sociabilidade burguesa.

A última consequência do pensamento pós-moderno decorrente de suas escolhas metodológicas associadas às analogias desenvolvidas a partir da linguística é que a efetivação de seu paradigma central, a análise da linguagem, é concebida em uma ordem puramente individual. Desse pressuposto se desenvolve uma razão expressa na linguagem, de forma implícita como elemento puramente subjetivo, produzindo uma verdade subjetivada, ensimesmada, impotente (ANDERSON, 1987).

O que se desenvolve desse percurso metodológico - associado à eliminação do sujeito coletivo - é a prevalência do indivíduo, ou seja, a exacerbação do ser individual que se efetiva no mais extremo individualismo. Na elevação do individualismo ao extremo está a mediação ideológica e cultural necessária para a adequação do ser social aos novos padrões do consumo estabelecidos pela racionalidade formal enquanto saída estratégica para a contenção das contradições entre produção e circulação.

Portanto, como vimos argumentando, o pensamento pós-moderno constitui um instrumento de domínio ideológico e cultural que oferta respostas subjetivas ao disciplinamento e ao controle da classe trabalhadora em um contexto específico da sociedade burguesa onde a intensificação do individualismo entra em oposição com as preocupações éticas e políticas e os conflitos sociais que a permeiam.

A cultura é ressignificada como meio de dominação ideológica da subjetividade do trabalhador ao cooptá-lo ao modelo do consenso e do diálogo entre trabalho e capital e sua consciente adequação aos parâmetros de consumo estabelecidos sobre a égide da racionalidade formal e da imposição de necessidades artificiais. A efetivação do cotidiano manipulado é possível diante da negação de uma resposta coletiva formulada sobre os conceitos de totalidade e mediação da razão dialética. Assim, a única resposta permitida apresenta um conteúdo "puramente" individual, isolando as questões sociais de todo e qualquer conteúdo coletivo. Assim a pulverização do poder e de seu domínio coletivo nas relações de classe é o modelo mais expressivo do desenvolvimento do pensamento irracionalista, o qual deságua na impossibilidade de afirmação do projeto histórico socialista e, consequentemente, na afirmação da eternidade da sociedade do capital.

\begin{tabular}{|l|l|l|l|l|}
\hline Q & Anista \\
\hline
\end{tabular}




\section{Referências Bibliográficas}

ANDERSON, Perry. Estrutura e Sujeito. In: ANDERSON, Perry. A Crise da Crise do Marxismo: introdução a um debate contemporâneo. São Paulo: Editora brasiliense, 1987.

COGGIOLA, Osvaldo. Universidade e Ciência na Crise Global. São Paulo: Xamã, 2001.

COSTA, Frederico. Elementos para compreensão do Pensamento Pós-moderno: O Irracionalismo como Subproduto da Crise do Capital. In: JIMENEZ, S. V.; RABELO, J. (Org.). Trabalho, Educação e Luta de Classes: a pesquisa em defesa da história. Fortaleza: Editora Brasil Tropical, 2004.

COUTINHO, Carlos Nelson. O Estruturalismo e a Miséria da Razão. 2 ed. São Paulo: Expressão Popular, 2010.

LUKÁCS, Georg. Existencialismo ou marxismo? São Paulo: Lech, 1979.

MARX, Karl \& ENGELS, Friedrich. O Manifesto Comunista. Tradução: Álvaro Pina. São Paulo, Editora Boitempo, 2002.

MARX, Karl. O Capital: crítica da economia política. Livro I. Tradução de Reginaldo Sant'Anna - 24 ed. - Rio de Janeiro: Civilização Brasileira, 2006.

MORAES, M. C. M. Recuo da Teoria. In: MORAES, M. C. M.; EVANGELISTA, O.;

TORRIGLIA, P. L. (ORG). Iluminismo as Avessas. Rio de Janeiro: DPeA, 2003.

TONET, IVO. Modernidade, Pós-modernidade e Razão. Disponível em: $<$ http://www.ivotonet.xpg.com.br/arquivos/MODERNIDADE_POS-

MODERNIDADE_E_RAZAO.pdf>, Acesso em 30 de abril de 2009.

\begin{tabular}{|c|c|c|c|c|}
\hline Q ovista Dialectus & Ano 2 & n. 5 & Agosto - Dezembro 2014 & p. $12-24$ \\
\hline
\end{tabular}

